\title{
From Private Supply Networks and Shared Supply Webs to Physical Internet Enabled Open Supply Webs
}

\author{
Helia Sohrabi ${ }^{1,2}$ and Benoit Montreuil ${ }^{1,2,3}$ \\ ${ }^{1}$ CIRRELT Interuniversity Research Center on Enterprise Networks, \\ Logistics and Supply Chains \\ ${ }^{2}$ Laval University, Québec, Canada \\ ${ }^{3}$ Canada Research Chair in Enterprise Engineering \\ \{Helia.Sohrabi, Benoit.Montreuil\}@cirrelt.ulaval.ca
}

\section{Introduction}

The way supply networks are designed has evolved through the years in order to address changes in the business environment, such as increasing customer service requirements, shortening of product life cycles and never ending pressures for inventory reduction. It is thus not surprising that hundreds of supply chain and supply network researches have been reported since the introduction of the concepts, focused on designing supply chains and networks so as to concurrently minimize logistics costs and maximize customer service in a turbulent and competitive environment.

Yet there are still evidences of supply network malfunctions in terms of stock excess, lost orders and unused facility space as the whole supply network is designed and planned at a strategic level long before operation time while the current business environment is fast changing. This urges the redesign of supply networks and their adaptation to real time business.

The Physical Internet (PI or $\pi$ ) recently introduced by Montreuil [1] offers a vision that can potentially enable a fundamental rethinking of supply network design. As one of its thirteen key characteristics, the Physical Internet empowers a global Open Supply Web (OSW) enabling producers, distributors, retailers and users to realize, move and store their products for fast, efficient and reliable response to quickly evolving demand. In such an Open Supply Web, products embedded in standardized modular containers can be dynamically deployed through an open geographically dispersed web of product realization centers, distribution centers, warehouses, hubs and transit centers. In an open supply web, the design of a supply network shifts from being in a strategic long-term decision territory to an operational and tactical decision making territory. It can be finely attuned to market conditions, efficient through better facility utilization and more reliable service to customers, and robust in responding to distributed stochastic demand.

This paper presents an exploratory research study aiming to assess the potential gains associated with moving away from the current ways of supply network design, expressed as Private Supply Networks and Shared Supply Webs, to the envisioned Physical Internet enabled Open Supply Web way. Section two proceeds with defining existing supply network designs and introducing further the concept of Open Supply Web. Section three presents the exploratory investigation, including numerical case 
generation and design optimization. Section four analyzes the experimental results. Section five concludes and synthesizes the value contribution of the paper, discusses its limitations, and provides future research avenues.

\section{On the Evolution of Supply Network Design}

Here we divide supply network designs introduced in the literature into two major groups; Private Supply Networks (PSN) and Shared Supply Webs (SSW). PSN are single-company focused. The design decisions are made in order to provide the company's products, from sourcing the required materials and components to producing and delivering final products to its clients in its targeted markets. When designing its supply network, the company is bound by a compromise between on one side providing better service and potentially gaining market revenues and on the other side requiring higher investments and incurring higher costs. This impacts its choices in terms of number, location and capacity of facilities in the network, and the service level that they are capable of offering and delivering to their clients in terms of speed and reliability. Illustrations of private supply network designs can be found in [2]-[6].

The compromise expressed above is a strong incentive for companies to engage in partnerships with each other, so as to share their production and logistic facilities as well as transportation means. Partnering companies aim to reduce both investments and operating costs associated with achieving their target service level. The synergistic coupling of their respective supply networks forms a shared network of supply networks, here called a shared supply web. Illustrations of shared supply web designs are discussed in $[7,8]$.

In the private supply network of a company, resources such as facilities are available only to that company. In shared supply webs, resources are available for exploitation in each partnering company's supply network. In a Physical Internet enabled open supply web, companies can exploit any openly available resource and deploy their products dynamically within this open web.

Open supply webs are characterized by (1) their nodes being openly accessible to any actor, be they producers, distributors, logistics providers, retailers or users; (2) the service capacity of their nodes available for contract on demand, on a per-use basis, be it for processing, storage or moving activities; and (3) by dynamic and interlaced virtual private networks created by actors to realize and deploy the products, services and solutions in anticipation of and response to real time business characteristics [1]. Table 1 contrasts the characteristics of existing private supply networks and shared supply webs with those of the proposed Open Supply Webs.

Except in special contexts, strategically designed private supply networks are hard to efficiently adapt to the real time demand and business environment. Shared supply webs allow a higher adaptability, yet are still constrained to the set of partnering companies and their strategic configuration of their shared supply web. When exploiting an open supply web, companies can readily adapt their supply network to the real time characteristics of demand and business environment. They can dynamically realize and deploy their products through a globally extended open web of available facilities. 
Table 1. Contrasting characteristics of existing private supply networks and shared supply webs with the proposed open supply webs

\begin{tabular}{cclll}
\hline $\begin{array}{c}\text { Supply } \\
\text { Network } \\
\text { design }\end{array}$ & $\begin{array}{c}\text { Decision } \\
\text { making } \\
\text { level }\end{array}$ & \multicolumn{1}{c}{ Facility utilization } & $\begin{array}{c}\text { Geographical } \\
\text { extension }\end{array}$ & $\begin{array}{c}\text { Customer service } \\
\text { level }\end{array}$ \\
\hline PSN & Strategic & $\begin{array}{l}\text { Poor as facilities are utilized } \\
\text { by a single company through } \\
\text { long-term contracts }\end{array}$ & $\begin{array}{l}\text { Constrained to } \\
\text { the single } \\
\text { company's } \\
\text { network }\end{array}$ & $\begin{array}{l}\text { Compromised by } \\
\text { location and } \\
\text { capacity of single } \\
\text { company's facilities }\end{array}$ \\
SSW & Strategic & $\begin{array}{l}\text { Improved relative to PSN but } \\
\text { still constrained to partnering } \\
\text { companies and long-term } \\
\text { commitments }\end{array}$ & $\begin{array}{l}\text { Constrained to } \\
\text { the shared web } \\
\text { of partnering } \\
\text { companies }\end{array}$ & $\begin{array}{l}\text { Compromised by } \\
\text { location and } \\
\text { capacity of } \\
\text { partnering } \\
\text { companies' facilities }\end{array}$ \\
& & $\begin{array}{l}\text { Improved by opening } \\
\text { available space to other } \\
\text { companies within short-term } \\
\text { contracts }\end{array}$ & $\begin{array}{l}\text { Flobally } \\
\text { extended }\end{array}$ & $\begin{array}{l}\text { Fast and reliable by } \\
\text { exploiting globally } \\
\text { dispersed open } \\
\text { facilities }\end{array}$ \\
\hline
\end{tabular}

Open supply webs are currently a vision. Some parts of this vision are dependent on the implementation of the Physical Internet. Some parts can be readily achievable by actors changing their worldview, their mental model of the best way to design supply networks, logistics and facilities.

\section{Exploratory Investigation}

An exploratory investigation of the potential of open supply webs relative to private supply networks and shared supply webs is introduced in this section. The studied context involves a set of companies, each having to design its supply network so as to best serve its targeted markets. The supply networks here embed factories to make products, distribution centers to serve clients, factory-DC flow links and DC-client flow links. Transportation is limited to truck travel. Here we have simplified the supply network design model to a location-allocation model and assumed that business characteristics such as demand and cost functions are deterministic. In forthcoming research, we plan to extend our investigation to uncertain environments requiring to model adaptability and robustness in a rigorous way, such as proposed in [9]. In the following subsections, the numerical case generation method and the optimization models are described.

\subsection{Case Generation: Business, Territory, Demand and Potential Sites}

The investigation has been bounded to a maximum of fifteen businesses, each producing a single product in a single factory and serving its targeted markets across the USA and Canada. This geographical area has been divided into 13 regions, four 
for Canada (northern territories are not considered due to their low population) and nine for the USA (based on US census regions).

Generating a case first involves generating for each company the locations of its customers, its overall demand and the demand from each customer, and the location of its factory. Second, generating a case requires generating the set of potential locations for opening distribution centers. The set of potential customer locations includes the 283 cities in Canada and the USA having a population larger than 100,000 inhabitants. Each company sells a distinct product whose price is randomly chosen between 200 and 400 \$. Annual sales of a company are randomly generated between $10^{7}$ and $10^{9} \$$. The number of served regions by a company is randomly generated. In each served region, a company has demand in a randomized number of cities, including those with higher population. In each served city, a randomized percentage of citizens are clients of a company. The annual demand in each city for the product of a company is computed from the company's overall demand by applying the ratio of the city's served population over the total number of clients served by the company. Each company's factory is randomly located in one of its served cities. Potential sites for distribution centers include 273 locations at the intersections of intercity highways. Distances between every potential site and every client city as well as every factory are calculated using their road distance from Google Map.

\subsection{Design and Assess: PSNs, SSWs and OSW}

In this section, the location-allocation models used to respectively optimize the design of each company-specific private supply network, the design of the shared supply webs and the design of the open supply web are described. The models use well known network modeling and integer programming techniques to support the goal of this research to compare performance of different companies designed in three different design modes and investigate the improvement achieved by exploiting an open supply web.

Here are the decision variables and parameters used across the three models.

$I_{s} \quad$ : Binary variable for the implementation of a distribution center in site $\mathrm{s}$

$A_{s c p}$ : Binary variable for the assignment of site $\mathrm{s}$ for servicing city $\mathrm{c}$ with company p product

$F_{s}$ : Non-negative continuous variable for the product flow through the distribution site s (one distribution center in PSN and SSW, a potential combination of open distribution centers in OSW)

$F_{p s}$ : Non-negative continuous variable for the flow of company's p product through the distribution site $\mathrm{s}$

$F_{s c p}$ : Non-negative continuous variable for the product flow from distribution site s to client city c for company p product

$c_{s} \quad$ : Throughput capacity of the distribution site $\mathrm{s}$

$d_{c p}$ : Client demand in city $\mathrm{c}$ for the product of company $\mathrm{p}$ 
$f_{p s}$ : Present value of unitary factory-to-site transport cost for site s served from the factory of company $\mathrm{p}$

$f_{s c p}$ : Present value of unitary transport cost of products of company $\mathrm{p}$ flowing from site $\mathrm{s}$ to client city c

$i_{s} \quad$ : Present value of distribution center implementation at site $\mathrm{s}$

$M \quad$ : A large number

$n \quad$ : Intended number of distribution centers to exploit

$t_{s c p}$ : Present value of site-to-city transport cost for serving from site $\mathrm{s}$ the entire demand for company's p product by clients in city c

First is the private supply network design model for a company with product $p$.

$$
\begin{array}{lll}
\text { Minimize } & \sum_{s}\left(i_{s} I_{s}+f_{p s} F_{p s}\right)+\sum_{s, c} t_{s c p} A_{s c p} \\
\text { Subject to } & \sum_{s} A_{s c p}=1 \quad \forall c \\
& \sum_{c} d_{c p} A_{s c p}=F_{p s} \leq M * I_{s} \quad \forall s \\
& \sum_{s} I_{s}=n
\end{array}
$$

In this mixed integer programming model, the objective function (1) is minimizing the total cost of opening new distribution centers, transporting products to client cities from their assigned distribution center, and transporting products from the factory to the distribution centers. Through constraint (2), each client city has to be served by a single distribution center. Constraint (3) insures that the flow through a distribution center equals the sum of the demands of all client cities assigned to it, and that no flow can go through it if it is not implemented. This flow is unconstrained, so that the distribution centers are capacitated as needed. Through constraint (4), the total number of implemented distribution centers is constrained to a specified number for experimental reasons.

Second is the shared supply web design model given previously existing private supply networks.

$$
\begin{array}{lll}
\text { Minimize } & \sum_{s, p} f_{p s} F_{p s}+\sum_{s, c, p} t_{s c p} A_{s c p} & \\
\text { Subject to } & \sum_{s} A_{s c p}=1 & \forall c, p \\
& \sum_{c} d_{c p} A_{s c p}=F_{p s} & \forall s, p \\
& \sum_{p} F_{p s}=F_{s} \leq c_{s} & \forall s
\end{array}
$$

The objective function (5) of the SSW is similar to that of PSN, except that it is summed over all companies' products and that there are no installation costs, reflecting the fact that in the experiment the partnering companies share the distribution centers that they installed when designing their private supply networks. Assignment constraints (6) are company specified, as contrasted to constraints (2) of 
the PSN. Constraints (7) compute the flow of company p product incoming each open distribution site s. Constraints (8) sum up the product flow of each company $p$ in each open site $\mathrm{s}$ and insure that the open site capacity is not exceeded. In the experiment, the capacity of each site is set equal to the total demand of the cities assigned to it in the PSN, plus an additional percentage experimented with three values $20 \%, 50 \%$ and $70 \%$. The site capacity is expressed in terms of product flow, assuming unit load equivalence among the products.

Third is the Supply Network Exploiting an Open Supply Web design model.

$$
\text { Minimize } \quad \sum_{s, p} f_{p s} F_{p s}+\sum_{s, c, p} f_{s c p} F_{s c p}
$$

Subject to constraints (8) and

$$
\begin{array}{ll}
\sum_{c} F_{s c p}=F_{p s} & \forall s, p \\
\sum_{s} F_{s c p}=d_{c p} & \forall c, p
\end{array}
$$

The objective function of OSW minimizes both distribution center feeding costs and client city serving costs, directly computing the flows instead of relying on assignment variables as in PSN and SSW since clients of each company p may be fed from multiple open distribution sites. Constraints (10) compute the flow of products form the factory of company $p$ to each open distribution site s. Constraints (8) are used to insure site capacity respect. Constraints (11) ensure that the demand of each client for the product of each company $\mathrm{p}$ is satisfied form the combination of open distribution sites.

In the OSW model, it is assumed that there is distribution center capacity openly available in each city. The capacity available in a city is considered to be a random number normally distributed with an average set as the total demand of all companies at that city plus an additional percentage (with four values 0, 10, 20 and 50\%). The capacity available at intersecting highway locations has been purposefully omitted. Companies exploit available spaces in the currently open distribution centers. To determine the open available capacity in the open supply web, first for each city the total demand over all companies is calculated. Then the closest distance between each site and all cities is calculated. Finally for each site a weighted summation of the closest cities' demand is calculated while the larger weights are assigned to the closer cities. In the experiment, to fix the site capacity, this value has been enlarged by 0,10 , 20 and $50 \%$ and the available capacity is set equal to a normal random number with average equal to any of these four values boosted 10, 20 and $50 \%$, resulting in twelve capacity scenarios.

\section{Analysis of Experimental Results}

The private supply network model described above has been solved for each of the fifteen generated companies for four variants each, respectively with one, three, five and ten distribution centers to be implemented. Fig. 1(a) presents as an illustration the optimized private supply network of a company having three distribution centers. 
The shared supply web model has been solved for three groups of companies, respectively with five, ten and fifteen partners. Again each of these has been optimized for four variants, respectively assuming that each partner company contributes one, three, five and ten distribution centers. Fig. 1(b) presents the optimized shared supply web for five partnering companies, each contributing three DCs.

The open supply web model has been solved assuming that all fifteen companies are to concurrently exploit it, under twelve distinct randomized capacity scenarios for open distribution centers. Fig. 1(c) displays the resulting massively meshed web, taking a collective perspective displaying the interplay of all flows from all companies, for a given capacity scenario. From an individual perspective, Fig. 1(d) displays the optimized flows associated with one company in the open supply web. Even in this simpler view, it is clear that the individual companies exploit widely more distribution centers than in the other settings, adapting their supply network much more finely to the distributed client demand.

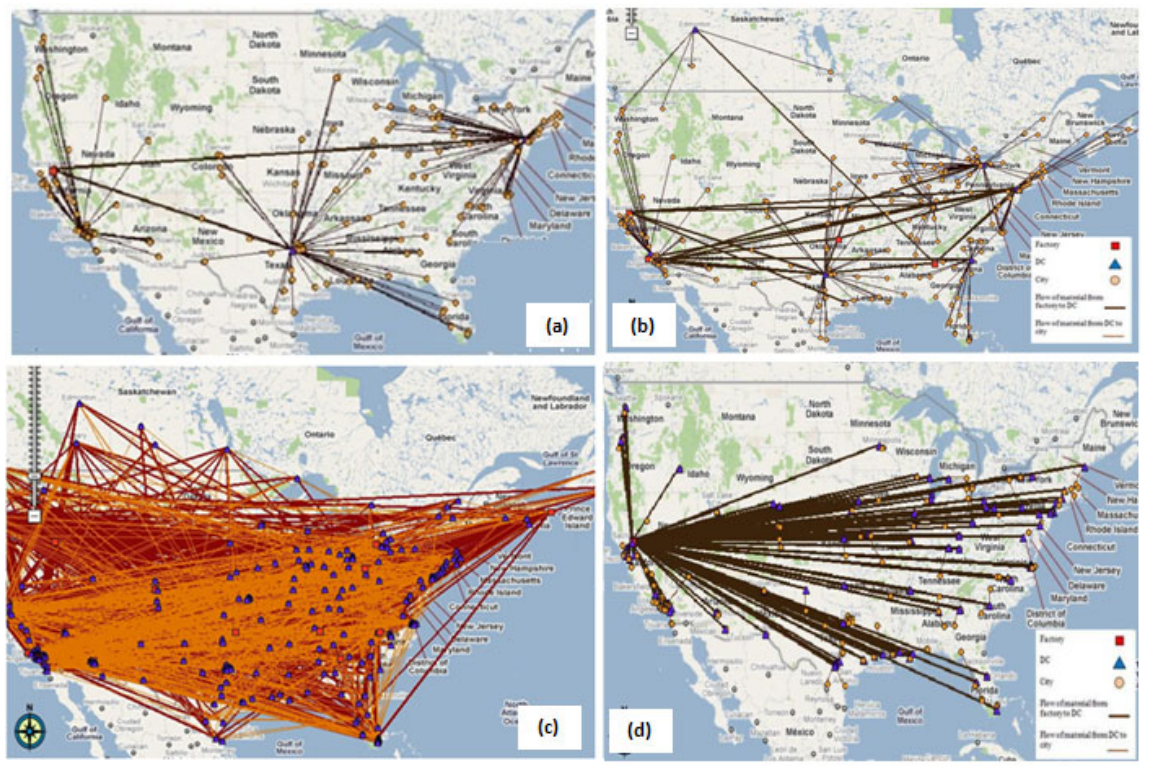

Fig 1. Map of a single company 's private supply network having three DCs (a), shared supply web of five partnering companies having three DCs each (b), Open Supply Web from collective perspective (c) and Open Supply Web from individual company perspective (d)

Table 2 provides a summary of the experimental results, based on model resolutions using the ILOG OPL 5.0 solver. As the three models have distinct objective functions, in line with the experimentation, instead of displaying them, for each set of designs Table 2 provides key comparable surrogate indicators extracted from analyzing the solutions: the scenario-based number of distribution centers available for exploitation as well as the number of distribution centers exploited in the optimal solution, the number of served cities and average delivery time offered to the customers. 
The delivery time results assume that each $500 \mathrm{~km}$ distance shipment by truck corresponds to a one-day delivery time, considering loading-unloading times and truck speed limits. By increasing the number of companies partnering in a shared supply web, the service coverage attained by private supply networks can be achieved by exploiting a significantly lower number of DCs. For example, when companies each contribute five DCs, the average service coverage is 16 hours exploiting their private supply network while it is 13 hours, 11 and 10 hours respectively when they collaborate in a shared supply web of five, ten and fifteen partners.

In the open supply web, all open distribution sites were available for usage. Out of these 273, 191 were indeed exploited, which is more than available in the biggest sharing strategic partnership in SSW scenarios. Without explicit strategic partnerships with other companies or significant investment, the achieved mean delivery time is 6 hours, which was achieved in the shared supply web only when at least 10 companies entered in a sharing strategic partnership, each contributing 10 distribution centers, engaging at least 100 facilities in which the partners had invested in. is 6 hours, achieved when 10 or15 companies each contributed ten DCs. In the two SSW scenarios where the 6-hour mean delivery time was achieved, the partners did not even exploit all their engaged facilities, 77 out of 100 in one scenario and 114 out of 150 in the other, thus leaving significant unused wasted space.

Table 2. Performance of each supply network design in terms of number of required DCs, mean and maximum delivery time served in the network

\begin{tabular}{lcccc}
\hline Supply network design & $\begin{array}{c}\text { Available } \\
\text { DCs }\end{array}$ & $\begin{array}{c}\text { Exploited } \\
\text { DCs }\end{array}$ & $\begin{array}{c}\text { Mean } \\
\text { Delivery } \\
\text { time [hr] }\end{array}$ & $\begin{array}{c}\text { Number } \\
\text { of served } \\
\text { clients }\end{array}$ \\
\hline Private supply network & 45 & 15 & 90 & \\
(Total over 15 companies) & 75 & 75 & 25 & 110 \\
& 150 & 150 & 9 & \\
SSW-5 companies- 1 DC each & 5 & 5 & 57 & \\
SSW-5 companies- 3 DC each & 15 & 12 & 19 & 573 \\
SSW-5 companies- 5 DC each & 25 & 22 & 13 & \\
SSW-5 companies- 10 DC each & 50 & 41 & 7 & \\
SSW-10 companies- 1 DC each & 10 & 9 & 54 & \\
SSW-10 companies- 3 DC each & 30 & 24 & 17 & \\
SSW-10 companies- 5 DC each & 50 & 40 & 11 & \\
SSW-10 companies- 10 DC each & 100 & 77 & 6 & \\
SSW-15 companies- 1 DC each & 15 & 12 & 51 & \\
SSW-15 companies- 3 DC each & 45 & 37 & 16 & \\
SSW-15 companies- 5 DC each & 75 & 63 & 10 & \\
SSW-15 companies- 10 DC each & 150 & 114 & 6 & \\
Open supply web & $\mathbf{2 7 3}$ & $\mathbf{1 9 1}$ & $\mathbf{6}$ & \\
\hline
\end{tabular}




\section{Conclusion and Research Perspectives}

This paper has contrasted the concepts of private supply networks, shared supply webs and open supply webs. It then investigated the potential of switching from the formers to an open supply web. The companies exploiting an open web have access to a wide number of open distributed facilities that they can use through short-term contracts without requirement to engage in large investments, long-term leasing or strategic partnerships. Therefore their supply networks can be redesigned in accordance to changes in the business environment of the operation time in an easy, cheap and quick way compare to the conventional supply network designs.

In order to explore the performance potential at stake, a case including 15 businesses serving clients in US and Canada were generated and optimized according to the three studied design alternatives. The results were highly conclusive.

Even though the added synergy potential made it clear that performance improvements were to be incurred when switching from the more restrictive to the more open alternatives, the amplitude of that gain has been highly significant and revealing. Open supply webs allowed companies to achieve the best service coverage by exploiting a large number of open DCs distributed throughout the territory while avoiding large investments, long-term leasing or long-term partnership commitments.

This exploratory investigation has clear limitations, with a case simplified to single-factory single-product companies, a low number of companies and potential sites, no dynamism consideration, known deterministic demand, no inter-company competition, only truck-based transportation, a geographical area limited to Canada and the USA, and performance measures limited to flow costs, investments, delivery time and number of sites available and exploited. Yet the obtained results confirmed the objectives of research, motivating further research toward investigating the potential of open supply webs under more comprehensive and realistic scenarios.

\section{References}

1. Montreuil, B.: Towards a physical internet: meeting the global logistics sustainability grand challenge. Logistics Research 3, 17 (2011)

2. Miranda, P.A., Garrido, R.A.: Incorporating inventory control decisions into a strategic distribution network design model with stochastic demand. Transportation Research Part E 40, 183-207 (2004)

3. Sabri, E.H., Beamon, B.M.: A multi-objective approach to simultaneous strategic and operational planning in supply chain design. Omega: The International Journal of Management Science 28, 581-598 (2000)

4. Vidyarthi, N., Elhedhli, S., Jewkes, E.: Response time reduction in make-to-order and assemble-to-order supply chain design. IIE Transactions 41, 448-465 (2009)

5. Goetschalckx, M., Vidal, C.J., Dogan, K.: Modeling and design of global logistics systems: A review of integrated strategic and tactical models and design algorithms. European Journal of Operational Research 143, 1-18 (2002)

6. Martel, A.: The design of production-distribution networks: a mathematical programming approach. In: Geunes, J., Pardalos, P. (eds.) Supply Chain Optimization. Kluwer Academic Publishers, Dordrecht (2005) 
7. Pan, S., Ballot, E., Fontane, F.: The reduction of green-house gas emissions from freight transport by pooling supply chains. International Journal of Production Economics, 9 (2010) (manuscript accepted, online access)

8. Nagurney, A.: A system-optimization perspective for supply chain network integration: the horizontal merger case. Transportation Research Part E 45, 1-15 (2009)

9. Klibi, W., Martel, A.: The design of effective and robust supply chain networks, research document CIRRELT. Laval University, 35 (2009) 